\title{
Magnetic signatures of ionospheric and magnetospheric current systems during geomagnetic quiet conditions - An overview
}

\author{
Olsen, Nils; Stolle, Claudia
}

Published in:

Space Science Reviews

Link to article, DOI:

10.1007/s11214-016-0279-7

Publication date:

2017

Document Version

Peer reviewed version

Link back to DTU Orbit

Citation (APA):

Olsen, N., \& Stolle, C. (2017). Magnetic signatures of ionospheric and magnetospheric current systems during geomagnetic quiet conditions - An overview. Space Science Reviews, 206, 5-25.

https://doi.org/10.1007/s11214-016-0279-7

\section{General rights}

Copyright and moral rights for the publications made accessible in the public portal are retained by the authors and/or other copyright owners and it is a condition of accessing publications that users recognise and abide by the legal requirements associated with these rights.

- Users may download and print one copy of any publication from the public portal for the purpose of private study or research.

- You may not further distribute the material or use it for any profit-making activity or commercial gain

- You may freely distribute the URL identifying the publication in the public portal

If you believe that this document breaches copyright please contact us providing details, and we will remove access to the work immediately and investigate your claim. 


\title{
Magnetic signatures of ionospheric and magnetospheric current systems during geomagnetic quiet conditions - An overview
}

\author{
Nils Olsen • Claudia Stolle
}

the date of receipt and acceptance should be inserted later

\begin{abstract}
High-precision magnetic measurements taken by LEO satellites (flying at altitudes between 300 and $800 \mathrm{~km}$ ) allow for studying the ionospheric and magnetospheric processes and electric currents that causes only weak magnetic signature of a few nanotesla during geomagnetic quiet conditions. Of particular importance for this endeavour are multipoint observations in space, such as provided by the Swarm satellite constellation mission, in order to better characterize the space-time-structure of the current systems.

Focusing on geomagnetic quiet conditions, we provide an overview of ionospheric and magnetospheric sources and illustrate their magnetic signatures with Swarm satellite observations.
\end{abstract}

Keywords Low Earth-Orbiting Satellites, Geomagnetic Quiet Conditions, Ionospheric and Magnetospheric Currents, Magnetic Field Modeling, Ørsted, CHAMP, Swarm

\section{Introduction}

Magnetic field measurements taken on ground (e.g. by the network of geomagnetic observatories) or in near-Earth space (by Low-Earth Orbiting satellites) provide a unique opportunity to study the Earth's interior and its environment. However, what is measured by a magnetometer in space or on ground is the superposition of contributions from various magnetic sources. The main part of Earth's magnetic field is caused by a self-sustaining dynamo operating in the fluid outer core (at depths greater than $2900 \mathrm{~km}$ below surface). On top of that there are fields caused by magnetized rocks in the Earth's crust

N. Olsen

DTU Space, Technical University Denmark, Diplomvej 371, DK-2800 Kongens Lyngby, Denmark, E-mail: nio@space.dtu.dk

C. Stolle

GFZ Potsdam, Telegrafenberg, 14471 Potsdam, Germany 
(the so-called crustal or lithospheric field), by electric currents flowing in the ionosphere, magnetosphere and oceans, and by currents induced in the Earth by the time-varying external fields. The separation of these various contributions based on observations of the magnetic field requires advanced modelling techniques (see e.g. Hulot et al. (2015) for an overview).

Determination of models that describe the Earth's magnetic field at a given location and time is called Geomagnetic modelling. As far as the Earth's core and crustal field is concerned, data from geomagnetic quiet days are usually selected, to minimize contributions from external (magnetospheric and ionospheric) sources. But when is "quiet" really quiet - what are proper criteria to select periods when external sources are weak? How to deal with the remaining part of external field contributions - what is their impact on models of the core and crustal field? And in turn: how have high precision magnetic field models been helpful in describing ionospheric and magnetospheric currents during quiet times, and what are still unresolved questions?

This review concerns magnetic field signatures of ionospheric and magnetospheric current systems during geomagnetic quiet conditions, focusing on phenomena studied with observations taken by high-precision satellite missions. We will discuss the scientific investigations that are possible with these data, and present highlights of the obtained results. Building upon our previous review (Olsen and Stolle 2012) we focus here on research that takes advantage of multi-point magnetic observations in space, as for instance provided by the three-satellite constellation mission Swarm.

But what characterises "high-precision magnetic satellites" like Orsted, CHAMP and Swarm? For ground measurements of Earth's magnetic field it is common to distinguish geomagnetic observatories, where the magnetic field vector is measured absolutely, and variometer stations, where only the field variations are measured, which means that the absolute level (the baseline) of the magnetic field is not known (and often vary with time, for instance due to temperature effects). Variometer data are therefore mainly used for studying temporal variations of the external field at periods (between seconds and days) shorter than that of the variability of the (unknown) baseline. Geomagnetic observatories, on the other hand, provide absolute observations of Earth's magnetic field, which also allows for investigating weak variations (of a few nanotesla) occurring over periods of weeks, months and years that are masked in variometer data due to their unstable baselines. The difference between magnetic observatories and variometer stations, and their application for scientific studies, is described in more detail in Chulliat et al. (this issue).

Also for satellites it is useful to distinguish between spacecraft that measure the magnetic field absolutely (i.e. with known baseline) and those which only observe magnetic field variations. The majority of magnetic satellites belong to the second category. Their data have been used very successfully for studying ionospheric and magnetospheric processes, especially during geomagnetic disturbed conditions when the signal of those sources is particularly strong (e.g., Knipp et al. 2014, and references therein). However, many interesting external phenomena have amplitudes of only a few nanotesla; still 
they provide crucial information on ionospheric and magnetospheric processes. Their proper investigation requires high precision measurements with wellknown baseline, preferably of magnetic field intensity and direction. Ørsted, CHAMP and the three-spacecraft constellation Swarm are examples of such high-precision magnetic satellite missions that collect magnetic vector data of accuracy $2 \mathrm{nT}$ and better.

To illustrate magnetic observations during geomagnetic quiet conditions, Figure 1 shows measurements at selected ground observatories at mid and low latitudes for 27 May 2009, which was an extremely quiet geomagnetic day (with index of global activity $K p$ between $0^{0}$ and $0^{+}$, and a $D s t$-index of magnetospheric ring-current amplitude between $-1 \mathrm{nT}$ and $+3 \mathrm{nT}$ ). During local night periods (Local Time (LT) between 18 LT and 06 LT), shown with thick lines, the Northward magnetic field component $X$ varies between $\pm 6 \mathrm{nT}$ around the baseline values (listed after the acronym of the observatory name). However, during daylight periods (thin curves) there are larger deviations due to ionospheric contributions with typical local time pattern (in this plot mainly from mid latitude $S q$ currents), e.g., maximum variations around local noon. But despite of being an extraordinary quiet day (the second quietest of the International $Q$-Days of May 2009) there are coherent (i.e. simultaneous, global-scale) field variations of a few nanotesla independent of day and night, such as the common structure at the observatories NGK, CLF, and VAL after 18:00 UTC.

CHAMP satellite magnetic observations for the same day, in dependence on magnetic latitude, are shown in Figure 2. The satellite was in a dawn-dusk orbit on that day (equator crossings at 05:10 LT, resp. 17:10 LT). The black dots present the $1 \mathrm{~Hz}$ residuals (observations minus field predictions from the CHAOS-6 model of Finlay et al. (2016) describing core, crustal, and large-scale magnetospheric magnetic contributions); the solid curves present mean values in $2^{\circ}$ bins in latitude with their corresponding \pm 1 -sigma uncertainty (shaded areas). Despite being an extremely quiet day, magnetic disturbances due to polar ionospheric currents at latitudes between $+65^{\circ}$ and $+85^{\circ}$ (Northern polar cap, sunlit) and between $-65^{\circ}$ and $-85^{\circ}$ (Southern polar cap, non-sunlit) are obvious, especially in the Eastward component $B_{\phi}$, which is the component strongest affected by field-aligned currents connecting the ionosphere with the magnetosphere.

It is also obvious from this figure that the magnetic vector components are typically more disturbed than field intensity $F$, in particular at polar latitudes, and that observations in sunlit regions (in this case at northern polar latitudes, corresponding to local summer) are more affected by external contributions compared to dark regions. We will discuss this in more detail in Section 3 with Swarm observations from two selected orbits.

Typically only satellite observations of field intensity $F=|\mathbf{B}|$ are used at polar latitudes when deriving models of the internal magnetic field, since $F$ is less affected by field-aligned currents compared to the magnetic vector components. However, $F$ contains magnetic signatures from Auroral or Polar Electrojets (PEJs) flowing in the ionospheric E-layer; their signature reaches 


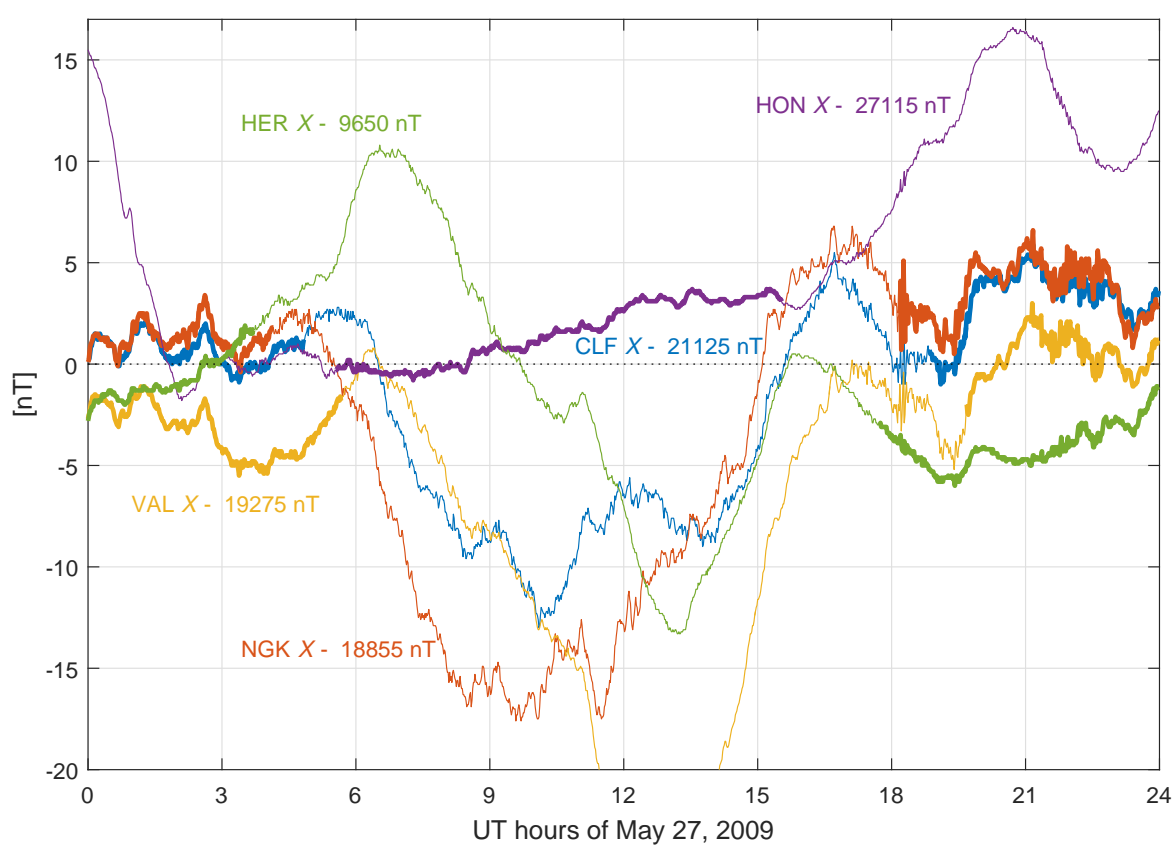

Fig. 1 Northward magnetic field component on 27 May 2009 as measured by the geomagnetic observatories Niemegk/Germany (NGK), Chambon-la-Foret/France (CLF), Valencia/Ireland (VAL), Hermanus/South Africa (HER) and Honolulu/USA (HON). The abscissa shows time in UTC. Local night periods (Local time between 18 and 06) are shown with thick lines; day periods with enhanced ionospheric contributions shown with thin lines.

amplitudes of $30 \mathrm{nT}$ and more even during quiet periods and in dark regions. The signatures in $F$ follow closely those in $B_{r}$ at high latitudes, since the field lines of the ambient magnetic field are almost vertical.

At nightside mid and low latitudes, where magnetic disturbances due to ionospheric currents are expected to be weak, all three vector components $\left(B_{r}, B_{\theta}, B_{\phi}\right)$ are typically considered, whereas no data (neither $F$ ) are used for magnetic field modelling at sunlit high-latitudes. The data that are typically discarded for modelling the core and crustal field (since either from sunlit regions or vector components from polar latitudes) are indicated by shaded grey in Figure 2.

Present geomagnetic field models describe the magnetic field observations within $2 \mathrm{nT}$ on average (as an example: for the Swarm-derived model of Olsen et al. (2016) the non-polar root-mean-squared difference between the observations used to derive the model and the model predictions varies between $1.9 \mathrm{nT}$ in $B_{r}$ and $3.0 \mathrm{nT}$ in $B_{\theta}$ ). Unmodeled ionospheric and magnetospheric field contributions are arguably the main contribution to this rms-misfit of a few nanotesla (which exceeds measurement accuracy by almost one order of magnitude), and a better description of the time-space structure of these contributions (in particular for the extremely quiet conditions that are considered 


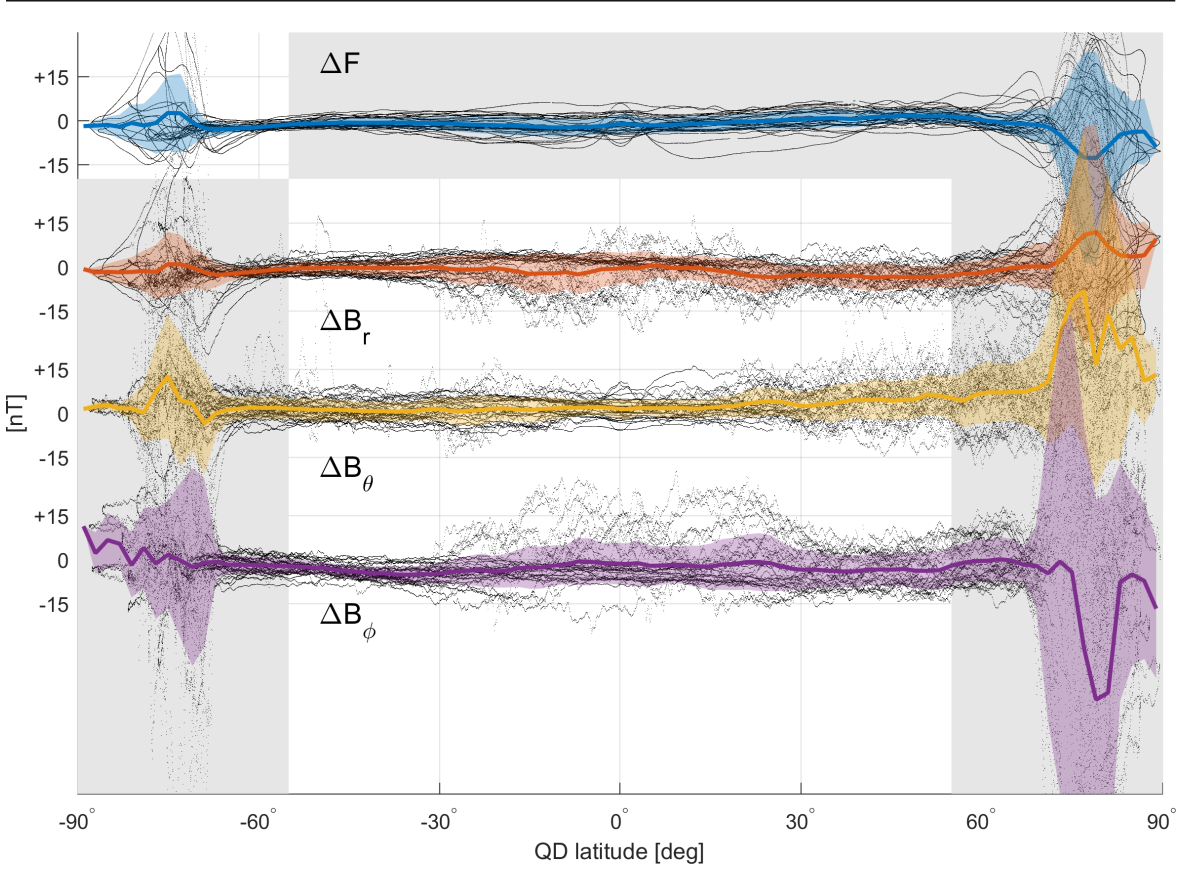

Fig. 2 CHAMP satellite magnetic field residuals for 27 May 2009 (after removal of core, crustal and magnetospheric values as given by the CHAOS-6 model of Finlay et al. (2016)) for the field intensity $F$ and the vector components $\left(B_{r}, B_{\theta}, B_{\phi}\right)$, in dependence on QD latitude (Richmond 1995). Data underlaid with grey are typically not used in geomagnetic field modelling.

in geomagnetic field modelling) will help to further improve models of the core and crustal field.

In following we give a short overview of ionospheric and magnetospheric current systems (section 2) followed by a discussion of their magnetic signature as seen in Swarm satellite constellation observations, with focus on spatial gradient observations (section 3). As an example for a weak but systematic magnetic signature that should be considered in geomagnetic field in order to further improve the models, we discuss in section 4 the magnetic effect of auroral field-aligned currents at mid and low latitudes.

\section{Electric currents in the ionosphere and magnetosphere during geomagnetic quiet conditions}

Extracting signals from electric currents during geomagnetically quiet conditions requires working with differences (residuals) between the magnetic observations and model values from high-resolution empirical magnetic field models, in order to remove the typically much stronger contributions from the core, crust and (for ionospheric studies) the magnetosphere. Multipoint observations from satellite constellation missions like Swarm enables an improved 
characterisation of the spatial and temporal structures of weak ionospheric processes: when using the difference of magnetic field measurements taken by close-by flying satellites. In that case the large-scale signals from the core and the magnetosphere will cancel out. The differences preserve, however, magnetic signatures at smaller scales (down to the separation of the spacecraft), thus allowing for investigating the time-space structure of electric currents in the ionosphere in a novel way. But also for these studies it is crucial to account for crustal field signatures since they occur at similar length scales and amplitudes as the ionospheric currents in consideration.

Ionospheric and magnetospheric contributions are typically rather different in polar, mid latitude, and equatorial regions. In addition, ionospheric signals are different on the day- and night side, mainly because ionospheric conductivity is greatly affected by solar irradiation, dropping essentially to zero in the ionospheric $E$-layer during night.

In following we give a brief overview about magnetic signatures of ionospheric and magnetospheric currents, with focus on investigations that take advantage of high-precision magnetic satellite missions. Figure 3 sketches current systems with relevant signatures in magnetic field observations.

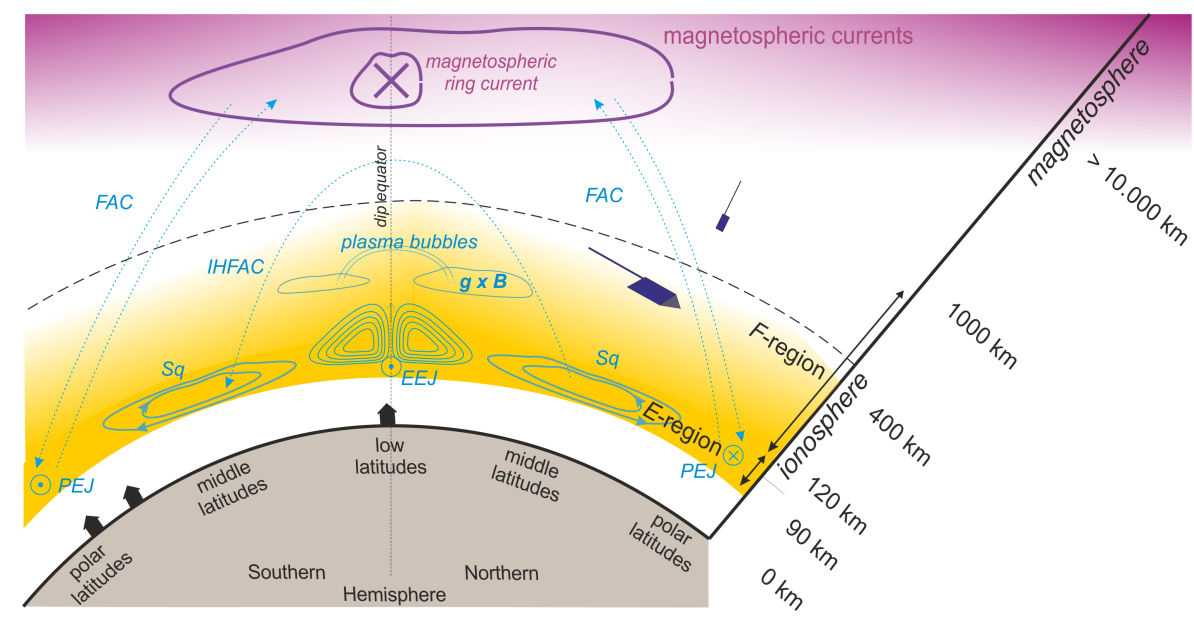

Fig. 3 Sketch of the various external sources contributing to the near-Earth magnetic field.

Magnetospheric currents. The main current systems in the magnetosphere are the Chapman-Ferraro currents flowing at the dayside magnetopause, the tail currents in the nightside magnetosphere, and the magnetospheric ring current in the equatorial plane at distances of few Earth radii. Classically, magnetospheric ring current activity is monitored by the Dst index (Sugiura 1964), derived from magnetic data at four ground observatories. The baseline of $D s t$ is determined for each local time hour from the five magnetically quietest days of each month, in an attempt to remove the slowly 
changing core field (secular variation). However, this procedure also removes some quiet-time signals of the ring current. Other indices monitoring the magnetospheric ring-current have therefore been suggested, derived from ground observatories and/or satellite observations (see Kauristie et al., this issue). One of them is the $R C$-index (Olsen et al. 2014), which is determined using data from up to 21 ground observatories after subtraction of the core field as given by a geomagnetic model. $R C$ is levelled to the average of quiet time data over several years (as opposed to the annual levelling of $D s t$ ). The variations of $R C$ clearly show an evolution of the ring current signatures of several nanotesla within weeks and months, similar to what is seen in satellite-derived indices of ring-current activity.

Since the baseline of ground observatory is undetermined (due to the static but unknown contribution from the regional crustal field in the vicinity of the observatory), the absolute value of the ring current signature during quiet times (that is the strength of the ring-current for zero value of $R C$ or $D s t$ ) can only be determined with high-precision geomagnetic LEO satellites. Sugiura et al. (1971); Sugiura (1972) and Sugiura and Poros (1973) used magnetic intensity measurements taken by the OGO satellite series to derive models of the magnetospheric ring current. Langel and Estes (1985a,b) extended these investigations and determined the ring current quiet time level (for $D s t=0$ ) to $-20 \mathrm{nT}$ based on data from the Magsat satellite. Using Ørsted and CHAMP observations, Maus and Lühr (2005) and Lühr and Maus (2010) further separated the large scale magnetospheric signatures into one part originating from the ring current, and another part originating from tail and magnetopause currents. Tail and magnetopause currents are found to be independent on solar flux variations, but the ring current contribution seems to vanish for very low solar flux. Correspondingly, Sabaka et al. (2015) revealed a quiet time ring current contribution of less than $-5 \mathrm{nT}$ for the years 2009 and 2010 (solar flux as low as $F_{10.7}=70 \times 10^{-22} \mathrm{Wm}^{-2} \mathrm{~Hz}^{-1}$ ) while nearly $-40 \mathrm{nT}$ were found for the solar maximum years 2002 and 2003.

The dependence of the ring current magnetic signal on local time has been investigated for moderate and active times using satellite and ground magnetic observations (e.g., Le et al. 2011; Newell and Gjerloev 2012). These authors found that the ring-current magnetic signature is several nanotesla stronger (more negative) in the evening (around 18 LT) compared to morning (around 06 LT). However, in-situ ring current observations derived from magnetometer observations of the Cluster mission revealed stronger currents on the dawn side compared to the dusk side (Zhang et al. 2011), reflecting a ring current local-time asymmetry opposite to that found in groundbased or LEO satellite magnetometer data. The reason for this difference is unknown but could be due to the fact that the Cluster satellites measure an in-situ current density while LEO satellites observe the integrated effect of all currents comprising the magnetospheric ring current and auroral FACs. The near Earth effects of large scale magnetospheric currents is discussed in more detail by Lühr et al. (this issue). 
A small, but significant difference in the amplitude of ring current magnetic signatures between LEO satellites and ground has been noticed in earlier years (e.g., Langel and Estes 1985b; Olsen 2002; Maus and Lühr 2005). Recently, Le et al. (2011) compared C/NOFS satellite observations with the Dst-index for selected geomagnetic storms and found that the satellite observations have only about $80 \%$ amplitude of the signatures at ground. Whether this difference is due to different processing of ground and satellite data, or whether it reflects an additional current flowing in the ionosphere (i.e. between ground and LEO satellite altitudes) as suggested by Fukushima (1989), is still unclear.

Ionospheric currents. The polar ionosphere is coupled to the magnetosphere via Field-Aligned Currents (FACs). Ionospheric E-layer currents, such as the polar electrojets, and FACs are always present, although of varying intensity depending on activity. They are caused by magnetospheric convection, mapping an electric field down to the ionosphere.

Minimum contributions from ionospheric and magnetospheric currents in polar regions are expected for dark conditions and low geomagnetic activity. Magnetic signals of few tens of nanotesla are attributed to the Polar Electrojets (PEJs) as is also seen in Figure 2, and later in Figures 4 to 6 of this article. Ritter and Lühr (2006) used CHAMP satellite magnetic observations to characterize the variability of external contributions at auroral latitudes for geomagnetic quiet and dark conditions. They found the strength of the PEJs to be neither correlated with the strength of FACs nor with solar wind parameters. However, there is a clear correlation for more active or sunlit times. Further investigations on possible statistical or physical relations to magnetospheric or solar wind proxies are needed to better characterize very quiet conditions at auroral latitudes - and thereby helping scientists deriving core and crustal field models to select data that are least contaminated by external sources.

Swarm constellation magnetic data enable to estimate the spatial and temporal scales of auroral FACs. Lühr et al. (2015) found that small scale currents (with horizontal scales of $<10 \mathrm{~km}$ ) persist for only $10 \mathrm{~s}$ and are locally confined, while currents of larger $(>150 \mathrm{~km})$ scales persist up to $60 \mathrm{~s}$. This analysis is based on data from the beginning of the Swarm mission when the three satellites flew in a "string-of-pearls-configuration", with only marginal longitudinal separation. FACs are assumed in that study to be organized as infinite extended current sheets, an assumption that, however, might not be valid in particular for small-scale FACs.

At mid latitudes, the prominent ionospheric currents are the $\mathrm{Sq}$ (solar quiet) currents of the ionospheric dynamo. This current system consist of two vortices with foci at about $\pm 30^{\circ}$ magnetic latitude centred around local noon and currents flowing anticlockwise in the Northern hemisphere, and clockwise in the Southern hemisphere when looking from above the ionosphere. Polar orbiting satellites measure along North-South oriented profiles, and are therefore well suited to resolve their global extension and variability. Pedatella et al. (2011); Sabaka et al. (2015) and Chulliat et al. (2016) derived climatological models of the mid latitude Sq. However, the Sq currents exhibit significant 
day-to-day variations (e.g., Yamazaki et al. 2011), that clearly need to be considered for single event analyses.

High-precision magnetic observations from LEO satellites can also resolve the weak interhemispheric field-aligned currents (IHFACs) that flow due to differences in the electrostatic potential between the two Sq vortices. Although their existence has been predicted in the 1960s by van Sabben (1966), it took more than 30 years to detect them in satellite observations (Olsen 1997). Lühr et al. (2015) studied their local time and longitudinal variations using Swarm satellite constellation data and found enhanced southward directed IHFACs during noon at longitudes of the South Atlantic Anomaly, suggesting that the weak core field in that region enhances the Sq current strength in the Southern hemisphere.

Magnetic signatures from Medium Scale Travelling Ionospheric Disturbances (MSTIDs) are detectable during dark conditions, when the effects from $\mathrm{Sq}$ is reduced, in the components perpendicular to the main magnetic field. MSTIDs are regionally confined nighttime dynamic plasma density irregularities in the ionospheric $E$ - and $F$-layers associated with electric field fluctuations that map to both conjugate hemispheres and thus produce significant IHFACs (Shiokawa et al. 2003). They have first been found by Saito et al. (1995) in electric measurements taken by the DE-2 satellite, and by Park et al. (2009) in magnetic field observations taken by the CHAMP satellite. Using data from the Swarm constellation, Park et al. (2015) confirmed that their spatial structure is similar to those of the associated plasma density fluctuations.

At dayside low latitudes the Equatorial Electrojet (EEJ) is the most prominent feature in magnetic observations at satellite altitudes. This current flows predominantly eastward along the magnetic equator within a band of $\pm 2^{\circ}$ latitude. Although the EEJ is known since many years from magnetic observations from ground (e.g., Onwumechili 1967; Forbes 1981), only satellite observations from Ørsted and CHAMP provided a global picture of the EEJ and its LT dependence (Ivers et al. 2003; Lühr et al. 2004). Alken and Maus (2007) derived a climatological model of the EEJ sheet current density based on Ørsted, SAC-C and CHAMP observations, describing its variability with longitude, season, local time, and solar flux. Comparing EEJ estimates based on CHAMP data with ground based magnetic data, Manoj et al. (2006) revealed a longitudinal correlation length of the day-to-day variability of the EEJ of $\pm 15^{\circ}$, which has been attributed to similar characteristic lengths of the ionospheric conductivity. Based on the side-by-side flying satellite Swarm Alpha and Charlie, Alken et al. (2015) investigated the gradient of the equatorial electric field. They revealed that also the longitudinal gradient of the electric field, similar to the electric field and the EEJ itself, exhibits significant longitudinal variability which is attributed to coupling to upward propagating atmospheric waves.

On the nightside, when the $E$-region conductivity is depleted, the low latitudes are affected by $F$-region diamagnetic and gravity driven currents in particular during the hours after sunset. Based on analyses from CHAMP and 
Swarm satellite observations, Alken (2016) found a correlation above 0.7 between in situ electron density and total magnetic field above the ionisation maximum (e.g., above $400 \mathrm{~km}$ altitude) which supports the significance of diamagnetic currents at these altitudes after sunset. The total field perturbations have been found to be up to few nanotesla before midnight and are strongest during equinoxes.

Diamagnetic and field-aligned currents associated with post-sunset plasma irregularities in the nightside ionosphere are yet another source of magnetic disturbances. They occur regularly after sunset at the equator at the bottom of the $F$-region. The structure rises, expands upward and extends poleward. The lifetime of these structures is between several minutes to hours (see, e.g., Woodman 2009, for a review). The magnetic signatures of these plasma irregularities have first been detected in LEO satellite data by Lühr et al. (2002), and their dependence on season, longitude and solar flux was determined by Stolle et al. (2006). Motivated by these observations, Yokoyama and Stolle (this issue) discuss physical modelling of post-sunset plasma irregularities to explain the observed magnetic signatures.

\section{On the spatial gradients of magnetic variations caused by ionospheric and magnetospheric currents}

High precision geomagnetic satellite missions in low Earth orbits are an important tool for studying ionospheric and magnetospheric current systems. Recently, also "differential data", either along satellite tracks (first time differences) from single satellites, or differences of measurements taken by close-by satellites, have provided further insight in small-scale structures of the upper atmosphere and magnetosphere, in particular those which are also present during quiet conditions.

To demonstrate the variability of magnetic field variations caused by electric currents in near Earth space, we will first present two exemplary events, representative for dayside and nightside conditions, followed by a statistical analysis of magnetic field variations and their variability for different local times. As pointed out by Fukushima (1994), “... complicated phenomena [...] must be discussed both statistically and for individual examples; these two different approaches are really complementary and not to be confronted each other".

\subsection{Two example orbits from the day-, respectively night-side}

Magnetic field intensity residuals along the dayside part of one orbit of the two Swarm satellites Alpha and Charlie are presented in Figure 4. The selected orbit, with an equatorial local time crossing at 12:12 LT, is from 2 May 2014, which was a geomagnetic quiet day $\left(K p<1^{+}\right.$and $\left.D s t>-13 \mathrm{nT}\right)$; the ground track of this orbit is shown in the lower right part of the figure. 
The left column (panels 4 a,d,g) shows observations from Swarm Alpha; the middle column (panels 4b,e,f) presents an estimate of the East-West gradient as measured by Swarm Charlie minus Swarm Alpha, divided by the distance between the two spacecraft; the right column (panels 4c,f,i) shows an estimate of the North-South gradient, obtained from 15-seconds alongtrack differences of Swarm Alpha divided by $d=141 \mathrm{~km}$ (which is the distance of two satellite measurements taken 15 seconds apart). For each of the three columns, the blue curves present the difference $\Delta F=F_{\text {obs }}-F_{\text {mod }}$ between observed magnetic intensity $F_{\text {obs }}$ and model values $F_{\text {mod }}$ as given by the CHAOS- 6 model of Finlay et al. (2016), whereas the red curves show model predictions.

Figure panels 4a,b,c present (blue curves) measurements minus core field model values, and (red curves) model predictions of the lithospheric field. The middle row of the figure (panels $4 \mathrm{~d}, \mathrm{e}, \mathrm{f}$ ) shows (blue curves) measurements minus model values of core and crustal field, and (red curves) model predictions of the magnetospheric field. Finally, panels $4 \mathrm{~g}$, h,i present (blue curves) measurements minus model values of the core, crustal and magnetospheric field, and (red curve) predictions of the ionospheric field as given by the CM5 model of Sabaka et al. (2015). The yellow curve in panel $4 \mathrm{~g}$ shows observations from satellite Swarm Charlie.

After subtracting the CHAOS-6 core, crustal and magnetospheric model predictions from the observations (blue curve of Fig. 4g) the signature of the Equatorial Electrojet is clearly visible at the magnetic equator $\left(0^{\circ} \mathrm{QD}\right.$ latitude) as a depression of magnetic field intensity $F$. The minima at about $\pm 30^{\circ}$ latitude probably reflect signatures of the mid latitude Sq current. Using ground magnetic observations, Yamazaki et al. (2011) identified the focus of $\mathrm{Sq}$ at about $30^{\circ}$ magnetic latitude, where the $Z$-component shows a local extreme and the North component minimizes. Stolle et al. (2016) present an Sq event as seen in Swarm satellite observations of December 2013; in this example the extreme in $F$ collocates approximately with the extreme in $Z$ and the North component minimizes at approximately the same latitude where $Z$ maximizes. The observations in Figure $4 \mathrm{~g}$ show similarity to these results. However, other current sources such as interhemispheric field-aligned currents, $F$ region currents or possible effects from ground conductivity have not been considered here. Substantial magnetic variations occur in the auroral regions, especially in the sunlit northern hemisphere where ionospheric conductivity is higher compared to the dark southern hemisphere, resulting in stronger Polar Electrojets.

The East-West gradient of $\Delta F$, shown in Figure panel 4 h, reveals maxima at the equatorial edges of the $\mathrm{Sq}$ current system, of up to $7 \mathrm{pT} / \mathrm{km}$ in this example. The gradient of the EEJ is smaller in magnitude than that of Sq, indicating rather weak East-West (i.e. local time) variation of the EEJ for the noon conditions presented here.

Panel 4i provides the South-North gradient, which for Sq is of similar amplitude compared to the East-West gradient. However, the signal of the EEJ is much larger in that gradient component, reflecting its narrow extension in latitude (thus resulting in a large South-North gradient) but extended struc- 
ture in longitude (i.e. small East-West gradient). The largest gradients occur, however, in the auroral regions and are caused by the PEJs.

We now shortly come back to the gradients of the mid-latitude signatures in Figures $4 \mathrm{~h}, \mathrm{i}$ to discuss possible contributions from the $E$-region Sq system or F-region currents. Alken (2016) published a statistical study of Swarm magnetic observations including alongtrack differences of the North component at mid- and low latitudes. Beside strong signatures around the dip equator he found a maximum/minimum of the alongtrack differences at about $15^{\circ}$, resp. $-20^{\circ}$, magnetic latitude during pre-noon hours, and suggested that those result from $F$-region diamagnetic and gravity driven currents being collocated with the crests of the Equatorial Ionisation Anomaly. Figure 4i does not indicate such a behaviour for this example, but rather reveals a maximum at $40^{\circ}$ magnetic latitude. Figure $4 \mathrm{~h}$ shows the East-West gradients in scalar intensity $F$ with maximum at $-10^{\circ}$ magnetic latitude. However, when comparing with Figures $4 \mathrm{k}$,i showing plasma densities, these extrema do not collocate with extrema in plasma density or plasma density gradients. We therefore conclude that gravity driven and diamagnetic $F$-region currents do not significantly affect Swarm observations during daytime when $E$-region currents are strong.

The gradients of the magnetospheric field as provided by the CHAOS- 6 model, shown in Figure panels 4e,f by the blue line, are rather different in the East-West and South-North gradients: While there is hardly any East-West gradient (i.e. CHOAS-6 model for satellite tracks Swarm Alpha and Charlie shows an almost identical magnetospheric (field), the alongtrack gradient has maxima at low latitudes, with changing sign between the hemispheres, as expected for the magnetic signature of the magnetospheric ring current. A difference in electron density of $0.2 \times 10^{6} \mathrm{~cm}^{-3}$ is expected to create a magnetic signal of about $0.2 \mathrm{nT}$ which is at the limit of detectability by high precision satellites (Stolle et al. 2006). In Figure 4 this would correspond to $1.4 \mathrm{pT} / \mathrm{km}$, anti-correlated with the plasma density gradient.

Figure panels $4 \mathrm{~g}, \mathrm{~h}, \mathrm{i}$ show (red curves) predictions of the ionospheric field as given by the CM5 model of Sabaka et al. (2015). The model describes the EEJ signatures in general rather well, and roughly reflects the amplitude of Sq for this example. This also holds for the South-North gradient; the ringing at northern mid latitudes is probably due to constraining the spherical harmonic expansion of the CM5 ionospheric field. The East-West gradients at mid and low latitudes are however not well described by CM5 in this example; they do for instance not show any of the observed features connected to the equatorward edges of Sq. Alongtrack gradient information from the CHAMP satellite contributed to CM5, and taking advantage of East-West gradient data from Swarm will likely improve the model further.

The red curves in the top row represent the magnitude (Figure 4a) and the gradients (Figures 4b,c) of the lithospheric field as given by the CHAOS-6 model. East-West and South-North gradients of the lithospheric field are of similar magnitude as the ionospheric signatures during day time; demonstrat- 

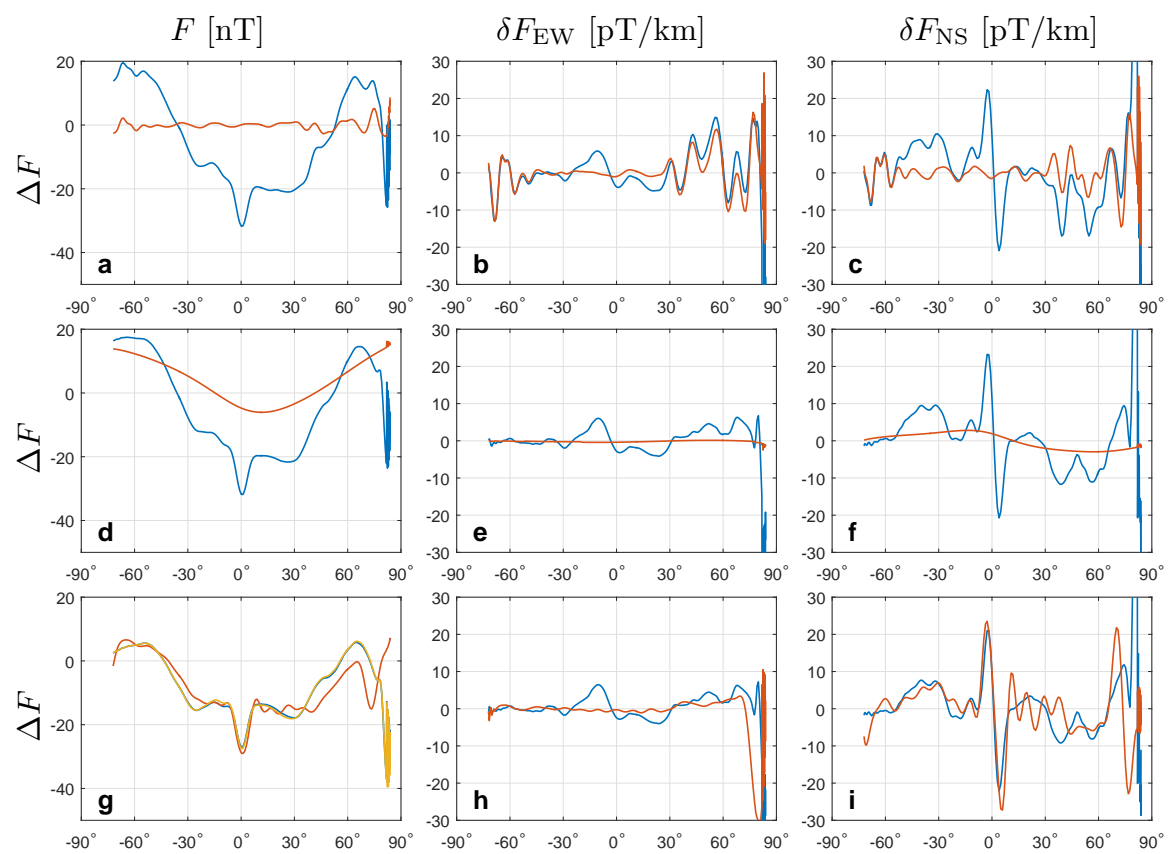

QD-latitude

QD-latitude
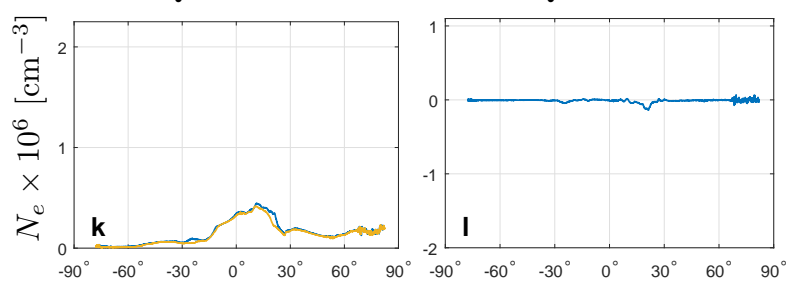

QD-latitude

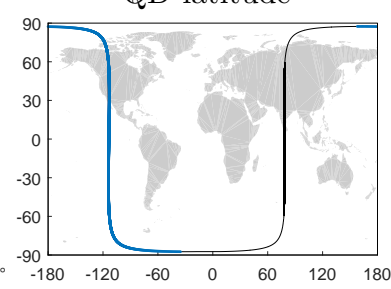

Fig. 4 Magnetic field intensity residuals for the day-time part of Swarm orbit number 2464 of 2 May 2014 vs. QD latitude. Equator crossing at 18:43:04 UT, corresponding to 12:12 Local Time.

$(\mathbf{a}, \mathbf{b}, \mathbf{c})$ : The blue curve shows the difference $\Delta F=F_{\text {obs }}-F_{\text {core }}$ between observed magnetic intensity $F_{\text {obs }}$ and the core field part $F_{\text {core }}$ as given by the CHAOS- 6 model. The red curve shows the crustal field model predictions. (d,e,f): The blue curve presents the difference between the two curves of panels $(a, b, c)$, i.e., the observed values minus model values for core and crust. The red curve shows the modelled contributions of magnetospheric currents. $(\mathbf{g}, \mathbf{h}, \mathbf{i})$ : The magnetic field intensity after removal of core, crustal and magnetospheric model values (shown by the red curves in panels d,e,f) is shown in blue. The red curves presents ionospheric current contributions as given by the CM5 model. Left panel shows values for Swarm Alpha; middle panel presents East-West gradients based on data from Swarm Charlie minus Swarm Alpha; right panel shows alongtrack gradients of Swarm Alpha.

Bottom: Electron density $N_{e}$ as measured by Swarm Alpha (left), and difference Swarm Charlie minus Swarm Alpha (middle). Ground track of the chosen satellite orbit, with highlighted dayside part, is shown in the bottom right panel. The yellow curves in panels $\mathrm{k}$ and 1 shows observations from satellite Swarm Charlie. 
ing the importance of accounting for lithospheric contributions when analysing ionospheric currents.

Electron density, shown in the bottom row of Figure 4, is highest at equatorial latitudes, indicating the strength of the equatorial ionisation anomaly at satellite altitude. Its East-West gradient (shown here as the difference of the observations taken by Swarm Charlie and Alpha) is rather small for this orbit and thus has only insignificant impact on the magnetic field. The magnetic field variations are therefore dominated by $E$-region and magnetospheric currents; diamagnetic effects due to electron density differences play only a very minor role.

$F$-region currents are much more important in the orbit presented in Figure 5. It shows magnetic field intensity residuals along a night side orbit on 25 October 2014 (local time of 20:30 LT). Although this was a day of slightly higher geomagnetic activity $\left(K p<3^{0}\right.$ and $\left.D s t \geq-30 \mathrm{nT}\right)$ it can still be considered as a geomagnetically quiet period. $E$-region conductivity is greatly reduced during night at low and mid latitudes, and thus no signatures from non-polar $E$-region currents are expected in the magnetic residuals shown in Figure 5g; they are indeed weak at these latitudes. Despite this, both Swarm Alpha and Swarm Charlie observe, at both sides of the magnetic equator, field depletions of few nanotesla which are interrupted by small-scale positive spikes. These spikes occur in the southern hemisphere for Swarm Charlie and in the northern hemisphere for Swarm Alpha. These variations are caused by diamagnetic $F$-region currents that arise due to steep plasma density gradients at post sunset local times. The bottom row of Figure 5 shows a well developed equatorial ionisation anomaly, characterized by a double hump to the north, respectively south, of the magnetic equator. Ionisation anomalies after sunset are frequently affected by equatorial plasma density irregularities at about $\pm 10^{\circ}$ magnetic latitudes, often called "plasma bubbles", for instance at $+10^{\circ}$ magnetic latitude for Swarm Alpha and at $-10^{\circ}$ magnetic latitude for Swarm Charlie in Figure 5. Although the amplitudes of their magnetic signatures are only few nanotesla, the obvious spatial anti-correlation between electron density and magnetic signature clearly identifies the origin of these signature in $F$.

The electron density measured by Swarm Alpha and Charlie shows spatial differences. Its increase from West to East (i.e. towards later local times) at the trough of the ionisation anomaly at the magnetic equator reflects the decrease of the magnetic anomaly, as expected for this local time (Liu et al. 2007). Indeed the magnetic signature between the two satellites decreases in response to the reduced diamagnetic effect. For the presented orbit, the magnetic field gradients due to post sunset electrodynamics are of similar magnitude as those in auroral regions. They are smaller in the magnetic South-North gradient compared to the East-West gradient since post-sunset plasma irregularities are likely aligned with the ambient magnetic field (e.g., Immel et al. 2003). Diamagnetic currents due to variations of the ionisation anomaly are discussed by Alken et al. (this issue). 

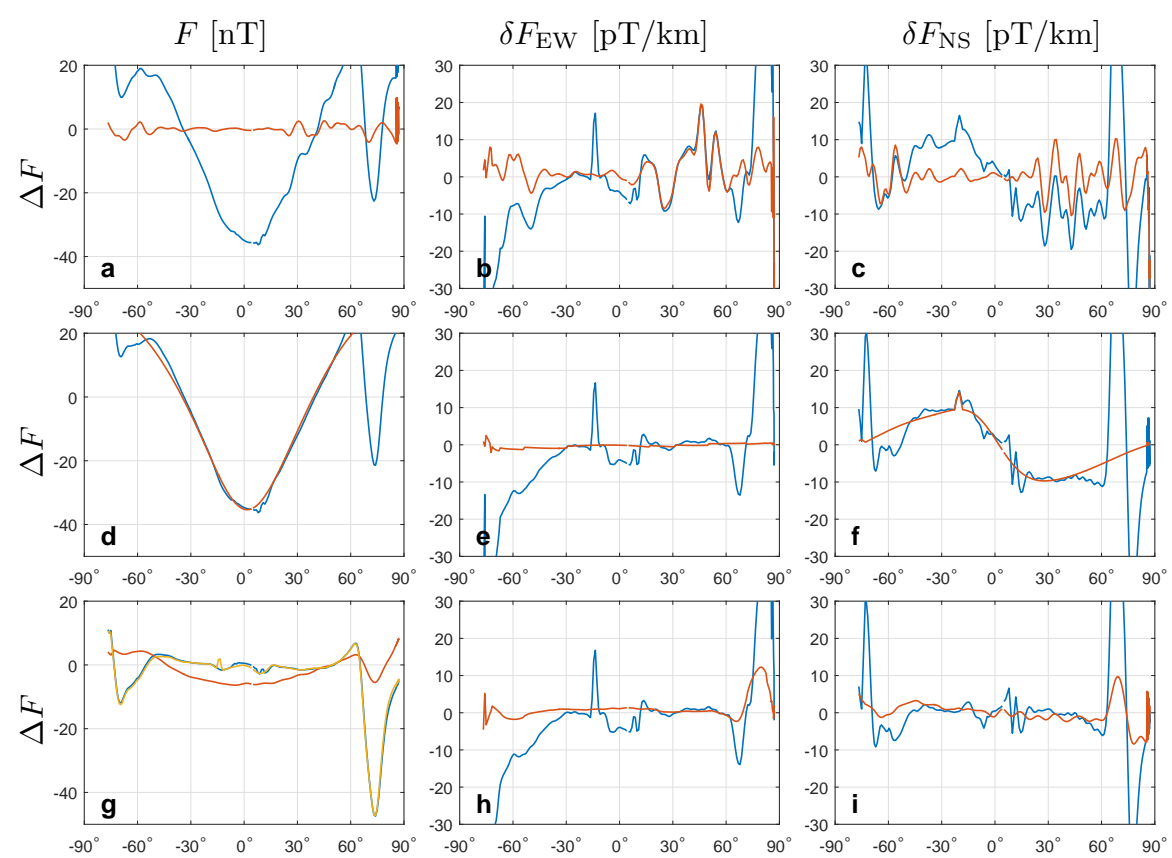

QD-latitude

QD-latitude
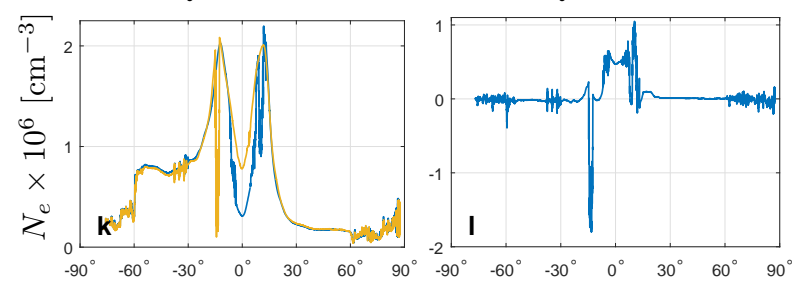

QD-latitude

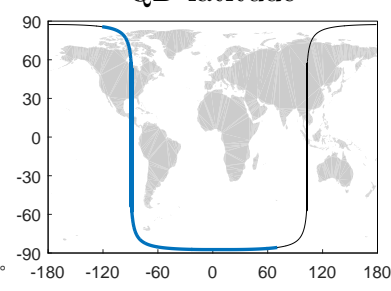

Fig. 5 Similar to Figure 4 but for the nightside part of Swarm Alpha orbit number 5151 on 25 October 2014. Equator crossing at 01:16:09 UT, corresponding to 20:30 Local Time.

\subsection{Statistical analysis}

A more comprehensive picture of the magnetic signatures of ionospheric currents at satellite altitude, including their horizontal gradients, is provided by a statistical analysis of two years (December 2013 to December 2015) of Swarm residuals (observations minus core, crustal and magnetospheric contributions as given by CHAOS-6, similar to what was shown in Figures $4 \mathrm{~g}, \mathrm{~h}, \mathrm{i}$ and $5 \mathrm{~g}, \mathrm{~h}, \mathrm{i}$ for single tracks) for quiet conditions $\left(K p \leq 2^{o},|d D s t / d t|<2 \mathrm{nT} / \mathrm{hr}\right)$. The top row of Figure 6 presents how the mean magnetic field residuals, for various LT windows, depend on QD-latitude; the black thick line shows data for "dark" conditions (sun at least $10^{\circ}$ below horizon, a selection criteria that is often used in geomagnetic field modelling). The bottom row presents the corresponding standard deviation $\sigma$. 
The most prominent features in all panels are the signatures of the Polar Electrojets at $\pm 70^{\circ}$ to $\pm 80^{\circ}$ magnetic latitude. Mean amplitudes reach $30 \mathrm{nT}$ even during the quiet conditions considered here, but with standard deviation $\sigma$ of similar amplitude. This indicates a considerable variability, reducing the significance of using average values to describe the PEJs. Similar to what is seen in the single orbit example of the previous section, the prominent current in the dayside equatorial regions is the Equatorial Electrojet. It develops in the morning, has its maximum around local noon, and decreases in the afternoon. Both the EEJ and the Sq current signatures are largest around noon (10 LT - 12 LT) and persist with significant amplitudes during post-noon (14 LT $18 \mathrm{LT})$, corresponding to remaining $E$-region conductivities during those local times. During night time, the mean values are, as expected, close to zero at
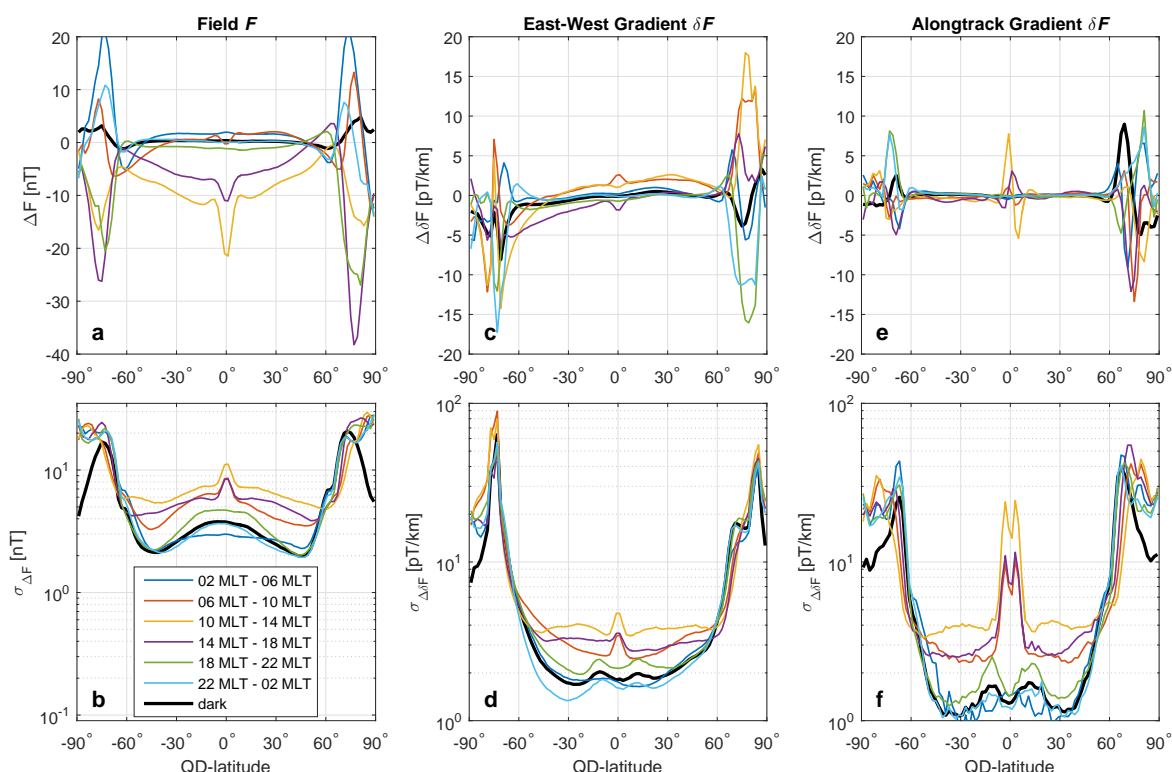

Fig. 6 Top: Mean value of field intensity residuals during quiet days, after removal of core, crustal and magnetospheric contributions, in dependence on QD-latitude and for various Local Time windows. Bottom: Corresponding standard deviation.

Left: Field intensity F; Middle: East-West gradient (based on difference Swarm Charlie minus Swarm Alpha); Right: Alongtrack gradient (based on first differences of 15 seconds data of Swarm Alpha).

non-polar latitudes, while at high latitudes significant variations occur at all local times as discussed in Section 2.

The non-polar $\Delta F$ is slightly positive in the morning (02 LT - 06 LT and $06 \mathrm{LT}-10 \mathrm{LT}$ ) and negative in the evening sector (18 LT - $22 \mathrm{LT}$ ), indicating a large-scale source that varies with local time but is not restricted to the dayside. Newell and Gjerloev (2012) found a local time dependence of the signature of the magnetospheric ring current, being strongest in the evening and 
weakest in the morning. A similar behaviour is seen in Figure 6a. Since these results are derived from differences between observations and model values including core, crustal and a magnetospheric contribution that has no local time dependence, the clear difference between dusk and dawn in the statistical analysis indicates an asymmetric magnetospheric ring current, extending the findings of Newell and Gjerloev (2012) (which were obtained for geomagnetic active conditions) to the quiet times considered here.

Standard deviations (Figure 6b) show enhanced variability of magnetic signatures near the equator for all local times, including night. This reflects the existence of remaining $F$-region currents, such as dynamo, gravity or pressure gradient driven currents that affect the total field also after sunset. These currents have longitudinal, seasonal and day-to-day variations for which we did not distinguish for in this graph, also contributing to observed standard deviations. The variability is smallest at post-midnight (02 LT - 06 LT) when $F$-region ionisation is lowest and the ionisation anomalies generally vanish (e.g., Stolle et al. 2011; Liu et al. 2007).

Figure 6c shows mean values of the East-West gradient of scalar intensity residuals. Significant gradients are expected in polar regions where the ionosphere is temporally and spatially highly dynamic due to intense magnetosphereionosphere coupling. At equatorial latitudes, the effect of the EEJ results in an increase of about $1 \mathrm{pT} / \mathrm{km}$ towards East in the morning and a decrease of similar amplitude in the afternoon, which is reasonable since the EEJ grows after sunset and decreases after noon. The East-West gradient is reduced around noon when the EEJ maximizes. In contrast, the Sq currents seem to have largest East-West gradients around noon.

Night side residuals show weak East-West gradients. Similar to Figure 6a, lowest gradients occur around midnight, with preferred offsets after sunset (18 LT - 22 LT) and before sunrise (02 LT - 06 LT). Apparently, also the gradient of the ring current signatures shows a local time asymmetry similar to that of the ring current itself.

Figure $6 \mathrm{~d}$ presents the corresponding standard deviations. Largest variability is found in polar and auroral regions. Variability of the mid latitudes Sq currents follows that of the gradient itself, with largest values around local noon. At equatorial latitudes the climatology and day-to-day variability of the EEJ is responsible for the local maximum of the standard deviation. Variability on the night side is much reduced although there are distinct peaks around $\pm 10^{\circ}-15^{\circ}$ magnetic latitude. They correspond to the peaks of the post sunset ionisation anomaly that has significant negative gradients toward later local times. This local time variation is not seen in the average gradients (panel 6c); its variability (panel 6d) is however significant. The relation to ionisation is further confirmed by the absence of this double peak at pre-sunrise. In general the East-West gradient and its variability (Figure 6c,d) is larger at polar compared to low and mid latitudes, for all local times.

The South-North (alongtrack) gradient for satellite Swarm Alpha is shown in Figure 6e. It is below $1 \mathrm{pT} / \mathrm{km}$ at mid latitudes, indicating weak ionospheric and magnetospheric contributions in the average alongtrack gradients. This is 
different at low and auroral latitudes where the EEJ and the PEJ cause gradients of up to $10 \mathrm{pT} / \mathrm{km}$. The standard deviation of the South-North gradient (Figure 6f) has about the same magnitude, or is even larger, as the gradient itself (Figure 6f) for all latitudes and local times, indicating the large orbitto-orbit variability of the alongtrack gradients. This variability is, however, lowest at middle latitudes during nighttime; the determined values of around $0.1 \mathrm{pT} / \mathrm{km}$ reflect probably the accuracy of the magnetic measurements of the Swarm satellites.

The black thick curves in all panels are obtained using data from "dark" conditions that are typically chosen for modelling of the Earth's internal magnetic field. At mid and low latitudes the black line follows mainly the behaviour of data around midnight (22-02 LT) with tendency toward the post-sunset structures $(18-22$ LT) especially for the standard deviations. The curves for pre-sunrise $(02-06 \mathrm{LT})$ are always less disturbed than the dark time curves. At polar latitudes, the selection for dark hours seems to improve the situation compared to the selected local times, but the amplitudes in both field strength and gradients are still significant, and further selection criteria or parametrization will have to be defined to further reduce residuals. Saying this, a lot of unexplained physics in the ionosphere/magnetosphere during very quiet times still needs to be understood.

\section{Magnetic signature of Region-1/2 Field-Aligned Currents at non-polar latitudes}

As an example of a weak but persistent magnetic signature at all latitudes we finally discuss the magnetic field caused by polar Field Aligned Currents (FACs).

Currents flowing along magnetic field lines of the ambient magnetic field, connecting the polar ionosphere and the distant magnetosphere, are more or less always present - even during geomagnetic quiet days. These Field Aligned Currents are mainly organized in East-West oriented sheets, resulting in in-situ satellite magnetic field variations in the East-West component $B_{\phi}$, and only marginal impact on the component $B_{\|}$in the ambient field direction (i.e. magnetic field intensity $F$ ). Satellite magnetic measurements of $B_{\phi}$ have therefore been used to investigate these current systems in the polar ionosphere. FACs on the high latitude side of the auroral zone are referred to as Region- 1 currents, while those on the low latitude side are referred to as Region- 2 currents, as sketched in the lower left panel of Figure 7. Maps of FACs in dependence on e.g. season and the Interplanetary Magnetic Field (IMF) have been derived by data from the satellites Dynamics Explorer-2 (e.g., Weimer 2001), Iridium constellation (e.g., Waters et al. 2001), Magsat and Ørsted (e.g., Christiansen et al. 2002) and CHAMP (e.g., He et al. 2012).

When flying through the auroral zones with their non-zero FACs, the magnetic field $\mathbf{B}$ measured by LEO satellites can not be represented as a Laplacian potential field, i.e. $\mathbf{B} \neq-\nabla V$ with $V$ as the magnetic scalar potential, due to 

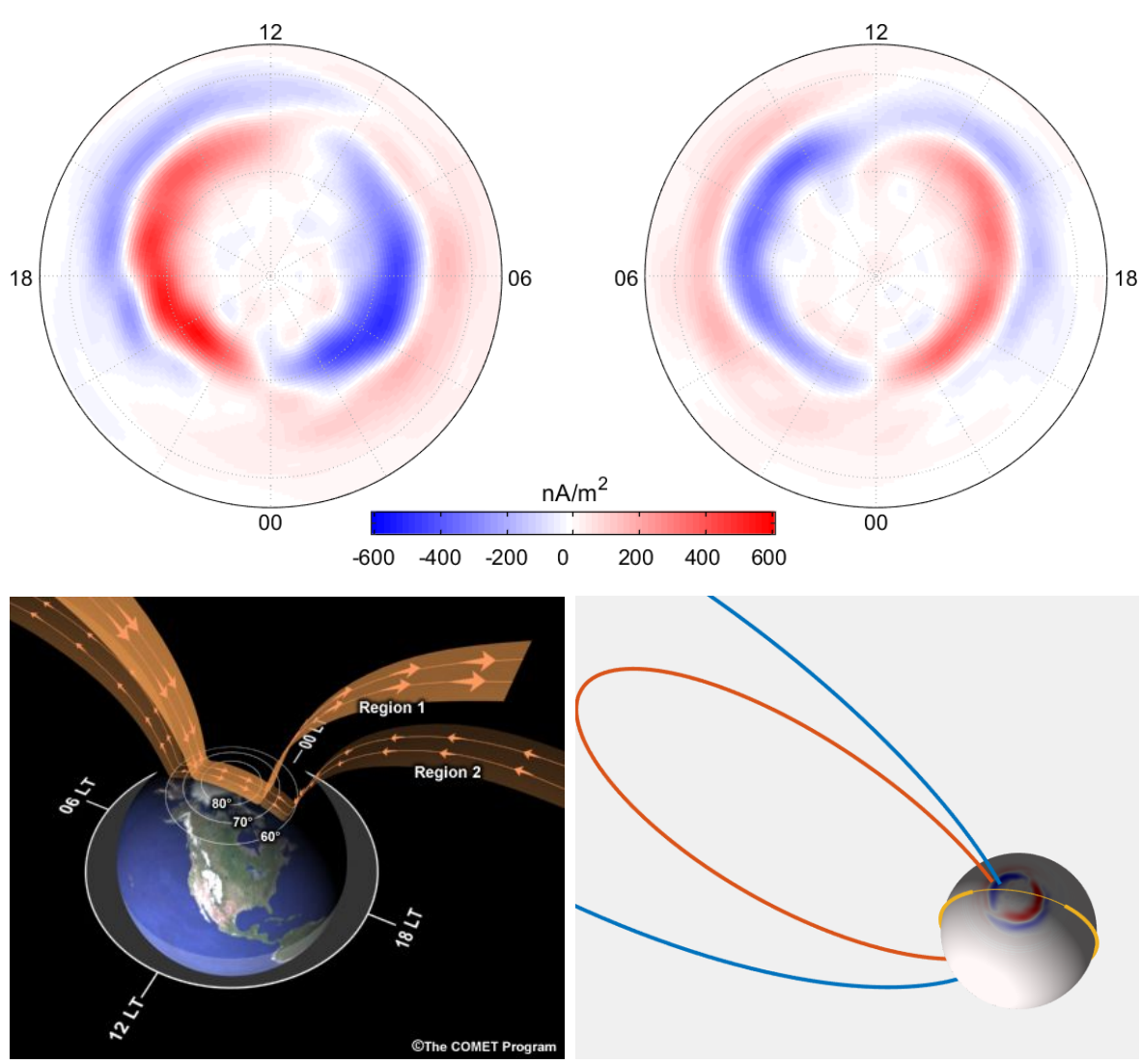

Fig. 7 Top: Radial current density at top of the ionosphere in the Northern (left), respectively Southern (right) polar cap, as determined by Laundal et al. (2016) (their Fig. 3) for Northern winter conditions, in dependence on QD-latitude and MLT. The equatorward boundary is at $\pm 55^{\circ}$ QD-latitude.

Bottom: 3D current system connection horizontal ionospheric currents with the distant magnetosphere through FACs. Left: Sketch of Region-1/2 currents. Right: Radial currents at top of the ionosphere and their closure through Region- $1 / 2$ currents. One satellite orbit is sketched in yellow, with QD latitudes equatorwards of $\pm 55^{\circ}$ highlighted.

non-zero current density $\mathbf{j}$, resulting in $\nabla \times \mathbf{B}=\mu_{0} \mathbf{j} \neq 0$. Outside the auroral zones, the current density at satellite altitude is close to zero (apart from possible inter-hemispheric currents, which, however, are much weaker compared to the auroral FACs, as discussed in section 2). Thus the magnetic field at middle and low latitudes (i.e. outside the auroral zone) is a Laplacian potential field and thus a representation $\mathbf{B}=-\nabla V$ is possible in those regions. However, a global representation of magnetic field variations, for instance using spherical harmonics, is still not possible since this would require $\nabla \times \mathbf{B}=0$ in the whole sampling shell, which means at all latitudes, as explained in more detail e.g. in Olsen et al. (2010). 
As mentioned above, Region- $1 / 2$ currents continue from the auroral ionosphere along field lines of the Earth's main field to the magnetosphere. The complete 3D current system comprises horizontal currents (PEJs) in the auroral ionospheric $E$-layer, FACs (the Region-1/2 currents) and closing currents in the distant magnetosphere. This 3D current system causes magnetic field variations at all latitudes, also in the non-polar regions where $\nabla \times \mathbf{B}=\mu_{0} \mathbf{j}=0$.

To investigate this effect we constructed a $3 \mathrm{D}$ current system from the radial current density $j_{r}$ at the top of the polar ionospheric $E$-layer as determined by Laundal et al. (2016) for Northern winter conditions and IMF $B_{z}<-1 \mathrm{nT}$ (see their Fig. 3). Their determined radial current density is shown in the top panel of Fig. 7. The complete 3D current system consists $(i)$ of horizontal sheet currents $\mathbf{J}_{H}$ in the ionosphere that are constructed from $\nabla \cdot \mathbf{J}_{H}=-j_{r}$ (taking advantage of the fact that the $3 \mathrm{D}$ current density $\mathbf{j}$ has to be divergence-free), ( $i i)$ of a current density $\mathbf{j}_{\|}$connecting the ionosphere and the magnetosphere along dipole field lines, and (iii) of closing currents in the distant magnetosphere (at distance of 20 Earth radii).

We determined the magnetic signatures produced by this $3 \mathrm{D}$ current system using the poloidal-toroidal decomposition approach of Engels and Olsen (1998). Figure 8 shows the obtained magnetic field variations for a typical satellite altitude of $400 \mathrm{~km}$. As expected, the largest amplitudes occur at auroral latitudes where the magnetic horizontal components reaches $90 \mathrm{nT}$ (170 nT) in $B_{\theta}$ in the Northern (Southern) hemisphere, and $140 \mathrm{nT}(210 \mathrm{nT})$ in $B_{\phi}$. Amplitudes are much smaller $(<17 \mathrm{nT})$ in the radial component $B_{r}$, and even smaller $(<6 \mathrm{nT})$ in field intensity $F$, as expected for magnetic fields mainly produced by FACs.

The magnetic signatures at low and mid latitudes have a pronounced local time dependence in each of its components. The small amplitude (of only a few nanotesla) and the large spatial scale makes their direct determination in magnetic field observations difficult. However, the whole current system follows some characteristics of the Region- $1 / 2$ currents that are part of it, for instance regarding dependence on the IMF. By studying the Region- $1 / 2$ currents one therefore can infer some characteristics of the low-latitude magnetic field signatures. Indeed a dependence of magnetic field signatures at non-polar latitudes on IMF $B_{y}$ has been recognized by Lesur et al. (2005) in satellite data, and by Vennerstrom et al. (2007) in ground data. Based on the found IMF dependence, Vennerstrom et al. (2007) suggested that the observed lowlatitude magnetic signature is caused by distant Region- $1 / 2$ currents.

The magnetic vector components of high-precision satellite missions like Ørsted, CHAMP and Swarm are calibrated (more precisely: aligned with the attitude data of the on-board star sensors) assuming that the observed magnetic field in non-polar regions can be described by a Laplacian potential field that is expanded in spherical harmonics. The above results suggest that this assumption is violated, which may have impact on the alignment of the magnetic vector components, in particular when only considering data from a short local time window. Proper accounting for non-polar magnetic signatures caused 
by polar Region-1-2 currents may therefore improve in-flight calibration of high-precision satellite data.
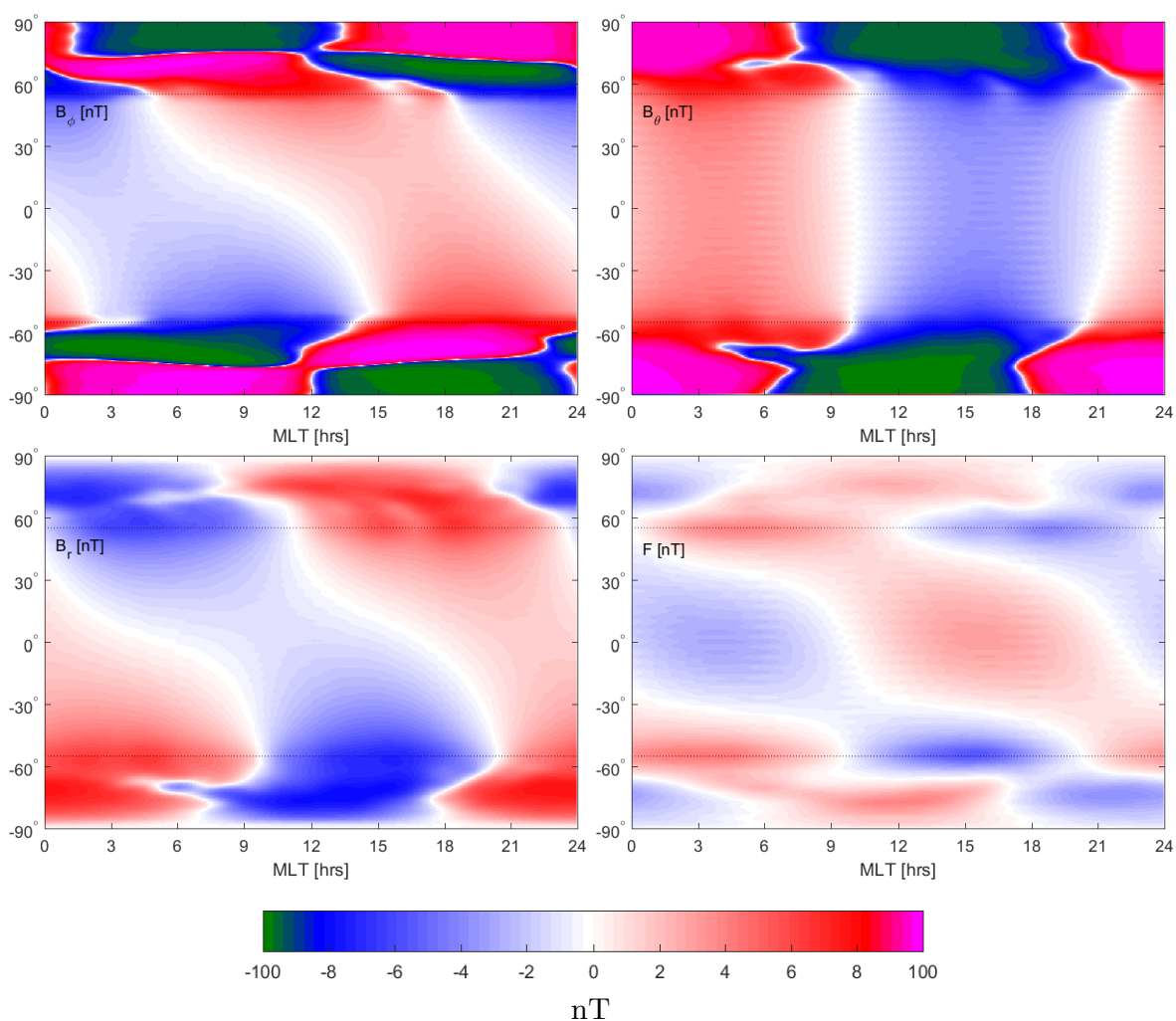

Fig. 8 Magnetic field at $450 \mathrm{~km}$ altitude produced by the $3 \mathrm{D}$ current system of Figure 7 . Magnetic field variations at QD latitude poleward of $\pm 55^{\circ}$ (dashed lines) reach $55 \mathrm{nT}$ in $B_{\theta}$ and $100 \mathrm{nT}$ in $B_{\phi}$.

\section{Conclusions}

Magnetic fields caused by ionospheric and magnetospheric currents show a significant variability and are almost always present, even during geomagnetic quiet periods as usually selected by low $K p$ indices and/or low magnitudes of the Dst-index. Much research has focused on phenomena at polar latitudes and for geomagnetic active conditions, due to the considerably larger amplitudes compared to non-polar regions and quiet conditions. However, the launch of high-precision magnetic satellites Ørsted, CHAMP and more recently Swarm stimulated an increased interest in investigations of electric currents in the Earth's environment during non-active conditions. 
There are at least three reasons for this increased interest, which is also manifested in this special issue of Space Science Reviews:

Firstly, it has been recognized that accurate modelling of the Earth's core and crustal field based on magnetic observations requires accounting for external field sources - either through proper data selection to minimize their impact, by removing their signature prior to using the observation for internal field modelling, or by co-estimating these external fields together with the model parts describing core and crustal fields. It is obvious that further improvement of geomagnetic models requires a better understanding of the characteristics of external sources during the geomagnetic quiet time periods that are used for internal field modelling.

Secondly, investigating the often rather weak magnetic fields of external currents during geomagnetic quiet conditions requires high-precision observations as well as high resolution models of the core and crustal field; Those are only available since year 2000 or so. The availability of more than one solar cycle of high-precision magnetic satellite data allows now for comprehensive investigations of even weak ionospheric and magnetospheric signatures, including their dependence on e.g. season, local time, solar cycle, and the IMF.

Thirdly, simultaneous multi-point high-precision magnetic data taken by the recently launched three-satellite constellation missions Swarm enables a novel way of characterising the space-time structure of ionospheric and magnetospheric sources.

We hope that our overview of magnetic field contributions during geomagnetic quiet days will increase the scientific interest in this topic and foster closer collaboration between experts in the various sources to Earth's magnetic field, be it of internal or external origin.

Acknowledgements We are very grateful to the International Space Science Institute Bern for giving us the possibility to take part in the Workshop on "Earth's Magnetic Field" held in Bern in May 2015.

\section{References}

P. Alken, Observations and modeling of the ionospheric gravity and diamagnetic current systems from CHAMP and Swarm measurements. J. Geophys. Res. 121(1) (2016). doi:10.1002/2015JA022163

P. Alken, S. Maus, Spatio-temporal characterization of the equatorial electrojet from CHAMP, Ørsted, and SAC-C satellite magnetic measurements. J. Geophys. Res. 112(A9), 09305 (2007). doi:10.1029/2007JA012524

P. Alken, S. Maus, A. Chulliat, P. Vigneron, O. Sirol, G. Hulot, Swarm equatorial electric field chain: First results. Geophys. Res. Lett. 42(3) (2015). doi:10.1002/2014GL062658

F. Christiansen, V.O. Papitashvili, T. Neubert, Seasonal variations of high-latitude fieldaligned currents inferred from Ørsted and Magsat observations. J. Geophys. Res. 107(A2), 1029 (2002). doi:10.1029/2001JA900104

A. Chulliat, P. Vigneron, G. Hulot, First results from the Swarm Dedicated Ionospheric Field Inversion chain. Earth Planets Space (2016)

U. Engels, N. Olsen, Computation of magnetic fields within source regions of ionospheric and magnetospheric currents. J. Atmos. Solar Terr. Phys. 60, 1585-1592 (1998) 
C.C. Finlay, N. Olsen, S. Kotsiaros, N. Gillet, L. Tøffner-Clausen, Recent geomagnetic secular variation from Swarm and ground observatories in the CHAOS-6 geomagnetic field model. Earth Planets Space 68, 112 (2016). doi:10.1186/s40623-016-0486-1

J.M. Forbes, The equatorial electrojet. Rev. Geophys. Space Phys. 19, 469-504 (1981)

N. Fukushima, Some topics and historical episodes in geomagnetism and aeronomy. J. Geophys. Res. 99(A10), 19113 (1994). doi:10.1029/94ja00102

N. Fukushima, Eastward Ring-Current at the Bottom of the ionosphere detected by $M A G S A T$, unpublished manuscript, 1989

M. He, J. Vogt, H. Lühr, E. Sorbalo, A. Blagau, G. Le, G. Lu, A high-resolution model of field-aligned currents through empirical orthogonal functions analysis (MFACE). Geophys. Res. Lett. 39(18), (2012). doi:10.1029/2012gl053168

G. Hulot, T.J. Sabaka, N. Olsen, A. Fournier, The Present and Future Geomagnetic Field, in Treatise on Geophysics (Second Edition), vol. 5, ed. by G. Schubert vol. 5 (Elsevier, Oxford, 2015), pp. 33-78. Chap. 02. ISBN 978-0-444-53803-1. doi:10.1016/B978-0-44453802-4.00096-8

T.J. Immel, S.B. Mende, H.U. Frey, L.M. Peticolas, E. Sagawa, Determination of low latitude plasma drift speeds from FUV images. Geophys. Res. Lett. 30(18) (2003). doi:10.1029/2003GL017573

D. Ivers, R. Stening, J. Turner, D. Winch, Equatorial electrojet from Ørsted scalar magnetic field observations. J. Geophys. Res. 108, 1061 (2003)

D.J. Knipp, T. Matsuo, L. Kilcommons, A. Richmond, B. Anderson, H. Korth, R. Redmon, B. Mero, N. Parrish, Comparison of magnetic perturbation data from LEO satellite constellations: Statistics of DMSP and AMPERE. Space Weather 12(1) (2014). doi:10.1002/2013SW000987

R.A. Langel, R.H. Estes, Large-scale, near-Earth magnetic fields from external sources and the corresponding induced internal field. J. Geophys. Res. 90, 2487-2494 (1985a)

R.A. Langel, R.H. Estes, The near-Earth magnetic field at 1980 determined from MAGSAT data. J. Geophys. Res. 90, 2495-2509 (1985b)

K.M. Laundal, C.C. Finlay, N. Olsen, Sunlight effects on the 3D polar current system determined from low Earth orbit measurements. Earth Planets Space (2016). submitted

G. Le, W.J. Burke, R.F. Pfaff, H. Freudenreich, S. Maus, H. Lühr, C/NOFS measurements of magnetic perturbations in the low-latitude ionosphere during magnetic storms. J. Geophys. Res. 116(A12), (2011). A12230. doi:10.1029/2011JA017026

V. Lesur, S. Macmillan, A.W.P. Thomson, A magnetic field model with daily variations of the magnetospheric field and its induced counterpart in 2001. Geophys. J. Int. 160(1), 79-88 (2005). doi:10.1111/j.1365-246X.2004.02479.x

H. Liu, C. Stolle, M. Förster, S. Watanabe, Solar activity dependence of the electron density in the equatorial anomaly regions observed by CHAMP. J. Geophys. Res. 112(A11) (2007). doi:10.1029/2007JA012616

H. Lühr, S. Maus, M. Rother, First in-situ observation of night-time $F$ region currents with the CHAMP satellite. Geophys. Res. Lett. 29(10), 127-1 (2002)

H. Lühr, S. Maus, M. Rother, Noon-time equatorial electrojet: Its spatial features as determined by the CHAMP satellite. J. Geophys. Res. 109(A1) (2004). doi:10.1029/2002JA009656

H. Lühr, S. Maus, Solar cycle dependence of magnetospheric currents and a model of their near-earth magnetic field. Earth Planets Space 62, 843-848 (2010). doi:10.5047/eps.2010.07.012

H. Lühr, J. Park, J.W. Gjerloev, J. Rauberg, I. Michaelis, J.M.G. Merayo, P. Brauer, Fieldaligned currents scale analysis performed with the Swarm constellation. Geophys. Res. Lett. 42(1), 1-8 (2015). doi:10.1002/2014gl062453

H. Lühr, G. Kervalishvili, I. Michaelis, J. Rauberg, P. Ritter, J. Park, J.M.G. Merayo, P. Brauer, The interhemispheric and $F$ region dynamo currents revisited with the Swarm constellation. Geophys. Res. Lett. 42(9), 3069-3075 (2015). 2015GL063662. doi:10.1002/2015GL063662

C. Manoj, A.V. Kuvshinov, S. Maus, H. Lühr, Ocean circulation generated magnetic signals. Earth Planets Space 58, 429-437 (2006)

S. Maus, H. Lühr, Signature of the quiet-time magnetospheric magnetic field and its electromagnetic induction in the rotating Earth. Geophys. J. Int. 162, 755-763 (2005) 
P.T. Newell, J.W. Gjerloev, Supermag-based partial ring current indices. J. Geophys. Res. 117(A5), (2012). A05215. doi:10.1029/2012JA017586

N. Olsen, K.H. Glassmeier, X. Jia, Separation of the Magnetic Field into External and Internal Parts. Space Sci. Rev. 152, 135-157 (2010). doi:10.1007/s11214-009-9563-0

N. Olsen, Ionospheric $F$ region currents at middle and low latitudes estimated from Magsat data. J. Geophys. Res. 102(A3), 4563-4576 (1997)

N. Olsen, A model of the geomagnetic field and its secular variation for epoch 2000 Estimated from Ørsted data. Geophys. J. Int. 149(2), 454-462 (2002)

N. Olsen, C. Stolle, Satellite Geomagnetism. Annu. Rev. Earth Planet. Sci. 40(1), 441-465 (2012). doi:10.1146/annurev-earth-042711-105540

N. Olsen, H. Lühr, C.C. Finlay, T.J. Sabaka, I. Michaelis, J. Rauberg, L. Tøffner-Clausen, The CHAOS-4 Geomagnetic Field Model. Geophys. J. Int. 197, 815-827 (2014)

N. Olsen, C.C. Finlay, S. Kotsiaros, L. Tøffner-Clausen, A model of Earth's magnetic field derived from two years of Swarm satellite constellation data. Earth Planets Space (2016)

C.A. Onwumechili, Geomagnetic variations in the equatorial zone, in Physics of Geomagnetic Phenomena, ed. by S. Matsushita, W.H. Campbell (Academic Press, ???, 1967), pp. $425-507$

J. Park, H. Lühr, C. Stolle, M. Rother, K.W. Min, J.K. Chung, Y.H. Kim, I. Michaelis, M. Noja, Magnetic signatures of medium-scale traveling ionospheric disturbances as observed by CHAMP. J. Geophys. Res. 114(A3), 03307 (2009)

J. Park, H. Lühr, G. Kervalishvili, J. Rauberg, I. Michaelis, C. Stolle, Y.-S. Kwak, Nighttime magnetic field fluctuations in the topside ionosphere at midlatitudes and their relation to medium-scale traveling ionospheric disturbances: The spatial structure and scale sizes. J. Geophys. Res. 120(8), 6818-6830 (2015). 2015JA021315. doi:10.1002/2015JA021315

N.M. Pedatella, J.M. Forbes, A. Maute, A.D. Richmond, T.-W. Fang, K.M. Larson, G. Millward, Longitudinal variations in the F region ionosphere and the topside ionosphereplasmasphere: Observations and model simulations . J. Geophys. Res. 116(A12), (2011). doi:10.1029/2011ja016600

A.D. Richmond, Ionospheric electrodynamics using magnetic Apex coordinates. J. Geomagn Geoelectr. 47, 191-212 (1995)

P. Ritter, H. Lühr, Search for magnetically quiet CHAMP polar passes and the characteristics of ionospheric currents during the dark season. Ann. Geophysicae 24(11), 2997-3009 (2006). doi:10.5194/angeo-24-2997-2006

T.J. Sabaka, N. Olsen, R.H. Tyler, A. Kuvshinov, CM5, a pre-Swarm comprehensive magnetic field model derived from over 12 years of CHAMP, Ørsted, SAC-C and observatory data. Geophys. J. Int. 200, 1596-1626 (2015). doi:10.1093/gji/ggu493

A. Saito, T. Iyemori, M. Sugiura, N.C. Maynard, T.L. Aggson, L.H. Brace, M. Takeda, M. Yamamoto, Conjugate occurrence of the electric field fluctuations in the nighttime midlatitude ionosphere. J. Geophys. Res. 100(A11), 21439-21451 (1995). doi:10.1029/95ja01505

K. Shiokawa, Y. Otsuka, C. Ihara, T. Ogawa, F.J. Rich, Ground and satellite observations of nighttime medium-scale traveling ionospheric disturbance at midlatitude. J. Geophys. Res. 108(A4) (2003). 1145. doi:10.1029/2002JA009639

C. Stolle, H. Lühr, M. Rother, G. Balasis, Magnetic signatures of equatorial spread $F$, as observed by the CHAMP satellite. J. Geophys. Res. 111, 02304 (2006). doi:10.1029/2005JA011184

C. Stolle, H. Liu, V. Truhlik, H. Lühr, P.G. Richards, Solar flux variation of the electron temperature morning overshoot in the equatorial F region. J. Geophys. Res. 116(A4) (2011). doi:10.1029/2010JA016235

C. Stolle, I. Michaelis, J. Rauberg, The role of high-resolution geomagnetic field models for investigating ionosphereic currents at low earth orbit satellites. Earth Planets Space 68, 110 (2016). doi:10.1186/s40623-016-0494-1

M. Sugiura, Hourly values of equatorial Dst for IGY. Ann. Int. Geophys. Year 35, 49 (1964)

M. Sugiura, B.G. Ledley, T.L. Skillman, J.P. Heppner, Magnetospheric-field distortions observed by OGO 3 and 5. J. Geophys. Res. 76(31), 7552-7565 (1971). doi:10.1029/ja076i031p07552

M. Sugiura, Equatorial current sheet in the magnetosphere. J. Geophys. Res. 77(31), 60936103 (1972). doi:10.1029/ja077i031p06093 
M. Sugiura, D.J. Poros, A magnetospheric field model incorporating the OGO 3 and 5 magnetic field observations. Planet. Space Sc. 21(10), 1763-1773 (1973). doi:10.1016/00320633(73)90167-0

D. van Sabben, Magnetospheric currents, associated with the N-S asymmetry of $S q$. J. Atmos. Terr. Phys. 28, 965-981 (1966)

S. Vennerstrom, F. Christiansen, N. Olsen, T. Moretto, On the cause of IMF By related mid- and low latitude magnetic disturbances. Geophys. Res. Lett. 34(16) (2007). doi:10.1029/2007gl030175

C.L. Waters, B.J. Anderson, K. Liou, Estimation of global field aligned currents using the Iridium System magnetometer data. Geophys. Res. Lett. 28(11), 2165-2168 (2001). doi:10.1029/2000gl012725

D.R. Weimer, Maps of ionospheric field-aligned currents as a function of the interplanetary magnetic field derived from Dynamics Explorer 2 data. J. Geophys. Res. 106(A7), 12889-12902 (2001). doi:10.1029/2000ja000295

R.F. Woodman, Spread $F$ - an old equatorial aeronomy problem finally resolved? Ann. Geophysicae 27(5), 1915-1934 (2009). doi:10.5194/angeo-27-1915-2009

Y. Yamazaki, K. Yumoto, M.G. Cardinal, B.J. Fraser, P. Hattori, Y. Kakinami, J.Y. Liu, K.J.W. Lynn, R. Marshall, D. McNamara, T. Nagatsuma, V.M. Nikiforov, R.E. Otadoy, M. Ruhimat, B.M. Shevtsov, K. Shiokawa, S. Abe, T. Uozumi, A. Yoshikawa, An empirical model of the quiet daily geomagnetic field variation. J. Geophys. Res. 116(A10) (2011). doi:10.1029/2011JA016487

Q.-H. Zhang, M.W. Dunlop, M. Lockwood, R. Holme, Y. Kamide, W. Baumjohann, R.-Y. Liu, H.-G. Yang, E.E. Woodfield, H.-Q. Hu, B.-C. Zhang, S.-L. Liu, The distribution of the ring current: Cluster observations. Ann. Geophysicae 29(9), 1655-1662 (2011). doi:10.5194/angeo-29-1655-2011 